\title{
E-book utilization among mathematics students of Universiti Putra Malaysia (UPM)
}

\begin{abstract}
Purpose: The purpose of this preliminary study is to identify the e-book utilization habit of postgraduate and undergraduate students from the Mathematics Department of Universiti Putra Malaysia (UPM), and to determine the reasons why students are feeling comfortable or uncomfortable with the e-book services offered by the library and the role the librarians can play in solving the identified obstacles. Design/methodology/approach: A qualitative approach which employs a face-to-face interview session was used to collect information on e-book utilization habit and to capture perception of the e-book services offered by UPM library. Findings: This research found that most of the participants use one common e-book reading habit. Factors such as easy access reduce physical visits to the library and userfriendly features offer a comfortable platform for the participant to use the mathematics ebooks. However, unreliable service, eye fatigue, lack of manipulability of online features and flaws in the physical design and insufficient e-book collection cause the participants to feel uncomfortable with the service. Moreover, the role of librarians, publishers and interface designers is perceived to be an important remedy for all the inconvenience incurred. Research limitations/implications: Only 70 participants participated in this preliminary study. Furthermore, e-books from a single publisher (SIAM) were used to collect data from the participants. Hence, the size of the population surveyed and usage of a single mathematics ebook publisher placed certain limitations on the level of detail in which the data collected could be analysed and summarised. Practical implications: The study is important in terms of obtaining a better understanding of e-book reading habits among mathematics students and the factors that cause them to feel comfortable and frustrated with the e-book service offered by the library. Originality/value: This is believed to be the first published study of mathematics students' reading habits and their perception using e-book in UPM.
\end{abstract}

Keyword: Academic libraries; Electronic books; Higher education 